MISES: Interdisciplinary Journal of Philosophy, Law and Economics

\title{
John Maynard Keynes and Ludwig von Mises on Probability ${ }^{1}$
}

\section{John Maynard Keynes e Ludwig von Mises sobre Probabilidade}

\author{
John Maynard Keynes e Ludwig von Mises sobre Probabilidad \\ Ludwig van den Hauwe - PhD em Economia, MsC em Finanças - ludwigvandenhauwe@gmail.com
}

Palavras-chave:

Probabilidade; Mises;

Keynes.

\section{Keywords: \\ Probability; Mises;}

Keynes.

Palabras clave:

Probabilidad; Mises;

Keynes.

\begin{abstract}
RESUMO
No que diz respeito aos pontos de vista sobre a probabilidade de Ludwig von Mises, é inegavelmente verdade que estes apresentam nuances consideráveis e que podem ser considerados como sendo de uma variedade sui generis. Mesmo que as visões de Ludwig von Mises sobre probabilidade exibam uma afinidade conceitual mais próxima com a filosofia de probabilidade de Keynes do que com a interpretação de frequência defendida por seu irmão Richard von Mises, uma importante diferença entre as visões de Ludwig von Mises e de John Maynard Keynes a esse respeito será, no entanto, reconhecido.

\begin{tabular}{l} 
ABSTRACT \\
As regards the views about probability of Ludwig von Mises, it is undeniably true that these display considerable \\
nuance and that they can be considered as being of a sui generis variety. Even if Ludwig von Mises's views on \\
probability exhibit a closer conceptual affinity with Keynes's philosophy of probability than with the frequency \\
interpretation espoused by his brother Richard von Mises, an important difference between the views of Ludwig \\
von Mises and those of John Maynard Keynes in this respect will nevertheless be acknowledged. \\
\hline RESUMEN \\
En lo que se refiere a los puntos de vista de Ludwig Von Mises sobre probabilidad, es innegablemente cierto que \\
éstos presentan matices considerables y que pueden considerarse como una variedad sui generis. Aunque sus \\
visiones exhiben una afinidad conceptual más cercana con la filosofía de probabilidad de Jonh Maynard Keynes \\
que con la interpretación de frecuencia defendida por su hermano, Richard von Mises, una importante diferencia \\
entre las visiones de Ludwig von Mises y de John Maynard Keynes a ese respecto fue, sin embargo, reconocida. \\
Classificação JEL: C25, B53, E12.
\end{tabular}
\end{abstract}

\footnotetext{
${ }^{1}$ Artigo publicado originalmente em inglês em: HAUWE, Ludwig Van Den. John Maynard Keynes and Ludwig von Mises on Probability on Journal of Libertarian Studies, v. 22. p. 471-507. Tradução de Matheus Pacini.
} 


\section{INTRODUÇÃO}

As questões complexas relativas à interpretação e ao significado de diferentes conceitos de probabilidade, bem como ao alcance legítimo de sua aplicação útil nas Ciências Sociais e na Economia pertencem a um dos subtópicos mais controversos do campo da metodologia econômica. Vários dos mais influentes economistas expuseram opiniões abertas sobre o assunto. Assim, provavelmente não é exagero afirmar que o segundo livro mais conhecido de John Maynard Keynes - depois de sua Teoria geral do emprego, do juro e da moeda - seja o seu Tratado sobre probabilidade. Os pontos de vista de Ludwig von Mises sobre probabilidade não foram apenas influentes no contexto da Escola Austríaca, mas muito além dela. Nesse sentido, alguns comentaristas alegaram que Ludwig von Mises basicamente adotou a interpretação de frequência da probabilidade de seu irmão Richard von Mises ${ }^{2}$, assim sugerindo que as opiniões de Ludwig von Mises sobre probabilidade não seriam menos antagônicas àquelas de John Maynard Keynes do que os seus pontos de vista sobre teoria econômica e políticas públicas. E é essa visão que será desafiada no presente trabalho. Embora não exista evidência histórica que aponte para qualquer influência histórica direta entre os pontos de vista sobre probabilidade desses dois autores, argumentar-se-á, em alguns aspectos relevantes, que os pontos de vista de Ludwig von Mises com respeito ao significado e à interpretação da probabilidade mostram uma afinidade conceitual mais próxima dos pontos de vista de John Maynard Keynes do que com os de seu irmão Richard von Mises.

Quanto às opiniões sobre probabilidade de Ludwig von Mises, é inegavelmente verdade que as mesmas exibem nuances consideráveis e que podem ser consideradas como sendo de uma variedade sui generis. Mesmo que as opiniões de Ludwig von Mises sobre probabilidade exibam uma afinidade conceitual mais próxima da filosofia de probabilidade de Keynes do que da interpretação de frequência defendida por seu irmão Richard von Mises. Uma diferença importante entre os pontos de vista de Ludwig von Mises e os de John Maynard Keynes será todavia reconhecida.

\footnotetext{
2 Veja, por exemplo, Hoppe (2006a), que assume que Ludwig von Mises é representante da interpretação de frequência de probabilidade. Defensáveis ou não, sobre as opiniões do autor sobre probabilidade, não é exatamente correto imputar esses mesmos pontos de vista a Ludwig von Mises. Além disso, não podemos detectar nenhuma conexão essencial ou exclusiva entre a economia de Keynes e os pontos de vista de Keynes sobre a probabilidade; assim sendo, uma rejeição da economia keynesiana veja, por exemplo, Hoppe (1992) não implica em uma rejeição dos pontos de vista de Keynes sobre probabilidade. Tentativas de forjar uma conexão supostamente essencial entre uma determinada visão filosófica (ideológica) ou econômica de mundo, por um lado, e uma interpretação particular da probabilidade, por outro, não são novas. Assim, como também é apontado em Lad (1983a), a interpretação objetiva de probabilidade parece ter sido bastante influente sobre a filosofia marxista-leninista e sobre o pensamento soviético sob a influência do modo de pensar do probabilista russo B.V. Gnedenko, que escreveu sobre a caracterização subjetiva da probabilidade dizendo que "o resultado final do uso consistente de uma interpretação tão puramente subjetivista da probabilidade é um inevitável idealismo subjetivo" $\left(2005\right.$, p. 25). O trecho também é citado em Lad [1983 ${ }^{\text {b }}$ p. 286). Contra esta interpretação, Lad $\left(1983^{\circ}\right)$ argumenta que uma interpretação operacional subjetiva à de Finetti está livre das cobranças de Gnedenko e melhor se adequa aos pressupostos filosóficos marxistas.
} 


\section{A SUMMA DIVISIO NA FILOSOFIA DE PROBABILIDADE: INTERPRETAÇÕES EPISTÊMICAS VERSUS INTERPRETAÇÕES OBJETIVAS DA PROBABILIDADE}

As interpretações de probabilidade são comumente divididas em (1) epistemológicas (ou epistêmicas) e (2) objetivas. As interpretações epistemológicas de probabilidade relacionam a probabilidade aos conhecimentos (ou crenças) dos seres humanos. Nesta abordagem, qualquer atribuição de probabilidade descreve um grau de conhecimento, um grau de convicção racional, um grau de crença ou algo do tipo. As abordagens de Ludwig von Mises e John Maynard Keynes pertencem a essa categoria. Em contraste, as interpretações objetivas de probabilidade consideram a probabilidade como uma característica do mundo objetivo material, que nada tem a ver com crenças ou conhecimentos humanos. A teoria de Richard von Mises pertence a esta categoria ${ }^{3}$.

Apesar de o próprio Ludwig von Mises ter claramente adotado uma interpretação epistemológica da probabilidade, a visão objetiva foi proposta por vários economistas austríacos, especialmente por aqueles que pertencem ao campo praxeológico. Aparentemente, tais autores dão como certo que Ludwig von Mises simplesmente adotou a filosofia de probabilidade de seu irmão Richard Von Mises. Assim, em uma passagem característica da obra Homem, economia e estado, M. N. Rothbard escreveu:

O contraste entre risco e incerteza foi brilhantemente analisado por Ludwig von Mises. Ele mostrou que eles podem ser integrados sob as categorias mais gerais de 'probabilidade de classe' e 'probabilidade de caso'. A 'probabilidade de classe' é o único uso científico do termo 'probabilidade' e é a única forma de probabilidade sujeita à expressão numérica (ROTHBARD, 2004. p. 553).

Nas duas notas de rodapé que acompanham essa passagem, Rothbard refere-se tanto à discussão de Ludwig von Mises na obra Ação humana, quanto à discussão de Richard von Mises na obra Probabilidade, estatística e verdade, combinando assim os pontos de vista dos dois irmãos ${ }^{4}$.

Interpretações como estas propostas por Rothbard são, na maioria das vezes, acompanhadas por uma rejeição consistente do uso de métodos quantitativos na realização de pesquisas aplicadas em Economia. Aqui, Rothbard conta a história dramática de como veio a abandonar o mundo da estatística:

Após frequentar todos os cursos de graduação em estatística, inscrevi-me em um curso de pós-graduação em estatística matemática na Columbia University com o eminente Harold

\footnotetext{
${ }^{3}$ As interpretações lógicas, subjetivas e intersubjetivas são todas epistemológicas. As interpretações de frequência e propensão são objetivas. Para fins de pesquisa e discussão das diferentes interpretações (GILLIES, $2000^{c}$ ).

${ }^{4}$ A interpretação de Rothbard é questionável devido a, pelo menos, dois motivos. Em primeiro lugar, Ludwig von Mises adota uma interpretação epistêmica do conceito de probabilidade de classe numérica, enquanto a interpretação de Richard von Mises com respeito ao conceito de probabilidade de frequência é objetiva. Em segundo lugar, enquanto que para Richard von Mises existe, de fato, apenas um uso científico do termo probabilidade, na perspectiva de Ludwig von Mises tanto o conceito de probabilidade de classe como o conceito de probabilidade de caso são cientificamente legítimos. Veja também outras referências mais adiante no texto. Para outras referências do professor Rothbard feitas à teoria de Richard von Mises, verificar particularmente Rothbard (1997), 24n, 24-27, 122n, 229n.
} 
Hotelling, um dos fundadores da economia matemática moderna. Após ouvir várias palestras dele, tive uma epifania: a percepção súbita de que toda a "ciência" da inferência estatística baseia-se em uma suposição crucial, e que tal suposição é totalmente infundada. Abandonei o curso de Hotelling e o mundo da estatística, para nunca mais voltar (ROTHBARD, 1995, p. 38 $\left.{ }^{a}\right)$.

Segundo o professor Rothbard, a suposição ou o pressuposto questionável é o seguinte:

Na ciência da estatística, a transição de nossas amostras conhecidas para uma população desconhecida depende de uma suposição crucial: a de que as amostras serão, em todo e qualquer caso - seja na análise de altura, desemprego ou intenção de voto - distribuídas em torno da variável 'população' de acordo com a chamada 'curva normal (ROTHBARD, 1995, p. $\left.38^{b}\right)$.

Declarações como essas foram severamente criticadas e mal interpretadas. David Ramsey Steele, em sua crítica à obra "O inimigo do estado: a vida de Murray N. Rothbard" (do autor Justin Raimondo), escreve:

Se o jovem Rothbard realmente tivesse encontrado algo que refutasse toda a teoria estatística, isso seria uma descoberta importante e um grande consolo para os produtores de tabaco. Contudo, 60 anos depois, o edifício da estatística não registrou qualquer tremor. $\mathrm{Na}$ visão de Rothbard-Raimondo, os estatísticos aceitam a Curva de Gauss por causa de um único exemplo, como a distribuição de pontos atingidos em torno do 'olho do touro' de um alvo. Na verdade, os estatísticos não veem a Curva de Gauss como sacrossanta. Devido ao fato de que muitos fenômenos ficam, de fato, muito perto da distribuição normal, de tal sorte que a suposição de distribuição normal virá a produzir previsões corretas, a distribuição normal pode ser tratada como uma generalização empírica e um instrumento útil. Alternativamente, a distribuição normal pode ser derivada estritamente do teorema do limite central, o qual mostra que quando alguma variável é influenciada por uma grande quantidade de variáveis aleatórias não relacionadas, aquela variável terá distribuição normal. Esse resultado está sujeito a certas condições que são amplamente, embora não universalmente, encontradas. Os estatísticos estão abertos à possibilidade de distribuições não normais às quais tais condições não se aplicam. Não parece que Rothbard tenha sido bem-sucedido na refutação de toda a ciência estatística por volta do ano de $1942 .{ }^{5}$

Essa interpretação da posição de Rothbard é certamente questionável. Não parece provável que Rothbard tivesse a pretensão de questionar a validade matemática do teoria do limite central ou de qualquer outro teorema do cálculo de probabilidade formal. Ainda pode ser verdade, no entanto, que naqueles contextos em que não existem coletivos aleatórios (ou seja, contextos caracterizados pela falta de repetições independentes), como muitas vezes se dá em Economia, as probabilidades objetivas não possam ser usadas. Como Rothbard adotou uma interpretação objetiva de frequência de probabilidade numérica, sua rejeição da estatística é um corolário defensável e logicamente consistente. Além disso, a rejeição do uso de probabilidades objetivas em Economia está de acordo com as conclusões de algumas das pesquisas mais recentes sobre o assunto, bem como com os argumentos gerais em prol da interpretação de

\footnotetext{
${ }^{5}$ O teorema do limite central (no sentido clássico) é o nome genérico de uma classe de teoremas que apresentam, em termos matemáticos precisos, as condições sob as quais a função de distribuição de uma soma adequadamente padronizada de variáveis aleatórias independentes é aproximadamente normal. Este teorema é um dos resultados mais notáveis de toda a matemática. Para uma introdução ao teorema do limite central de uma perspectiva histórica (STEELE, 2000). Veja também W. J. Adams (1974).
} 
probabilidades em Economia mais como epistemológicas do que como objetivas (GILLIES, $\underline{\left.2000^{a}\right)^{6}}$.

Vale ressaltar que, por muito tempo, tal visão objetiva também foi bastante influente em certos círculos marxista-leninistas. Considerando que a visão objetiva tinha sido dominante na teoria e na prática estatísticas durante a maior parte do século anterior, foi principalmente em certos escritos soviéticos que se fizeram tentativas para prover a visão objetiva com fundamentos filosóficos supostamente marxista-leninistas e, logo, descartar a caracterização subjetiva da probabilidade como se ela inevitavelmente levasse ao idealismo subjetivo. ${ }^{7}$

Entretanto, a questão crítica que queremos examinar aqui é se os preceitos da metodologia e epistemologia praxeológicas envolvem um compromisso exclusivo com o ponto de vista objetivo. O exame do ponto de vista de Ludwig von Mises a esse respeito não nos convenceu de que este é realmente o caso.

Na verdade, conforme já mencionado anteriormente, o ponto de vista de Ludwig von Mises com relação à interpretação da probabilidade é mais próximo do ponto de vista de Keynes do que o da filosofia de probabilidade de seu irmão Richard von Mises. Para fundamentar essa visão, compararemos a posição de Ludwig von Mises com as posições de John Maynard Keynes e de Richard von Mises. As duas abordagens principais à interpretação da teoria da probabilidade que serão aqui consideradas são, portanto, a interpretação de frequência sistematizada por Richard von Mises e a interpretação lógica sistematizada por John Maynard Keynes. ${ }^{8}$

\footnotetext{
${ }^{6} \mathrm{O}$ principal motivo para que as probabilidades objetivas não possam ser validamente introduzidas na economia não é muito difícil de entender e pode estar relacionado à impossibilidade de introduzir uma noção satisfatória de repetições independentes das condições e de amostras aleatórias e homogêneas. Em uma situação experimental típica em física, uma sequência de repetições independentes do experimento é perfeitamente possível. O experimento pode ser realizado no mesmo laboratório em dias diferentes ou em laboratórios diferentes no mesmo dia, e essas repetições serão tipicamente independentes: as condições necessárias para a introdução de probabilidades objetivas estão satisfeitas. Pode parecer que haja uma certa semelhança estrutural entre uma situação típica em economia e uma situação experimental na Física. Os dois casos, todavia, diferem em aspectos importantes. Não poderíamos usar observações do comportamento e desempenho dos sistemas econômicos como amostras de repetições independentes de condições semelhantes às presentes em experimentos regulares de Física? As amostras diferentes poderiam ser retiradas de qualquer (1) dados relacionados ao mesmo sistema econômico em momentos diferentes, ou (2) dados relacionados a diferentes sistemas econômicos em um estágio de desenvolvimento semelhante. Um autor que reexaminou recentemente essas questões resume sua resposta da seguinte maneira: "No primeiro caso, se as amostras se referem a 'retratos' da economia muito próximos no tempo, é difícil sustentar que o desempenho mais recente não seja influenciado pelo desempenho dos períodos anteriores; portanto, a independência das amostras não pode ser mantida. Se as amostras se relacionam a períodos históricos suficientemente distantes uns dos outros para tornar plausível a suposição de independência, é improvável obter amostras homogêneas; invalidando assim o 'experimento'. No segundo caso, o uso de uma amostra de dados transversais ainda não seria capaz de conferir-lhes independência, pois os sistemas econômicos tendem a ser integrados em termos de comércio e produção, particularmente na medida em que o fluxo de informações de um país provavelmente afetará o comportamento dos fatores atuantes em outros países." Tal visão em relação à interpretação da probabilidade é, portanto, ditada pela natureza fundamentalmente diferente dos fenômenos sob estudo no campo da ação humana quando comparados a fenômenos físicos. Os agendes em uma economia de mercado são muito diferentes, digamos, das moléculas de um gás. Como um sistema econômico é composto por indivíduos atuantes, com pensamentos e crenças distintos, uma repetição independente de qualquer situação torna-se difícil, senão impossível (GILLIES, 2000 d, p. 187 e 192).

${ }^{7}$ Nesse sentido, pode-se chamar a atenção para a influência de Gnedenko, autor da obra Teoria da probabilidade, muitas vezes revista e reimpressa, contendo uma caracterização objetiva do acaso e, ao mesmo tempo, a declaração mais completa da compreensão soviético-marxista acerca da probabilidade. Veja também a discussão em Lad (1983d).

8 Tais interpretações correspondem em geral - embora não exatamente - aos dois conceitos de probabilidade de Carnap: o da probabilidade usada na lógica (grau de confirmação), por um lado, e o da probabilidade usada na estatística e na física (frequência
} 
$\mathrm{Na}$ terceira e na quarta seção a seguir, apresentarei uma caracterização geral das visões sobre probabilidade desses dois autores. Na quinta seção, argumentarei que a tese de que Ludwig von Mises teria adotado a interpretação de frequência de seu irmão Richard von Mises é discutível em função de várias declarações do próprio Ludwig von Mises sobre o assunto.

Na sexta seção, também examinarei se, e em quais aspectos, os pontos de vista de Ludwig von Mises sobre a probabilidade exibem, de fato, exibem uma afinidade conceitual com a interpretação de probabilidade de John Maynard Keynes. Na sétima seção, destacar-se-á uma importante diferença entre as respectivas opiniões de Ludwig von Mises e de John Maynard Keynes sobre a probabilidade.

\section{A ABORDAGEM OBJETIVA DE RICHARD VON MISES SOBRE A PROBABILIDADE: A INTERPRETAÇÃO DE FREQÜÊNCIA}

O principal objetivo de Richard von Mises era fazer da teoria da probabilidade uma ciência semelhante às demais ciências. De acordo com a visão de frequência, a teoria da probabilidade é considerada uma ciência da mesma ordem, digamos, da geometria ou da mecânica teórica. Ele critica a visão de que a probabilidade pode ser derivada da ignorância: "foi afirmado - e isto não é exagero - que, enquanto outras ciências tiram suas conclusões daquilo que sabemos, a ciência da probabilidade deriva seus resultados mais importantes daquilo que não sabemos" (MISES, R., 1981, p. 30a).

A probabilidade deve basear-se na existência - e não na ausência - de fatos. A teoria da frequência relaciona uma probabilidade diretamente ao real mundo através de fatos objetivos observados (ou dados correspondentes) retirados, em especial, de eventos repetitivos.

Como Richard von Mises colocou:

Por meio dos métodos de abstração e idealização cria-se um sistema de conceitos básicos sobre o qual, então, uma estrutura lógica pode ser erguida. Devido à relação original entre os conceitos básicos e os fenômenos primários observados, essa estrutura teórica nos permite tirar conclusões sobre a realidade do mundo. (MISES, R., 1981, p. 30 b)

$\mathrm{Na}$ abordagem lógica a ser examinada na próxima seção, a teoria da probabilidade é vista como um ramo da lógica, como uma extensão da lógica dedutiva ao caso indutivo. Em contraste a essa visão, a abordagem de frequência considera a teoria da probabilidade como uma ciência matemática, tal como a mecânica, porém lidando com uma gama distinta de fenômenos observáveis. A probabilidade não deve, portanto, ser interpretada em sentido epistemológico. Não 
é a falta de conhecimento (incerteza) que fornece a base da teoria da probabilidade, mas o contato com um grande número de eventos.

Uma teoria da probabilidade que não apresente desde o início uma conexão entre probabilidade e frequência relativa em nada será capaz de contribuir para o estudo da realidade (MISES, R., 1981, p. 30). Uma questão-chave levantada por essa visão se refere a como as ciências matemáticas se relacionam com o material empírico que buscam analisar. Como Richard von Mises era um empirista, o seu ponto de partida era sempre um fenômeno observável como, por exemplo, um coletivo empírico. Na verdade, de acordo com a definição de frequência aleatória, é possível falar sobre probabilidades apenas em referência a um coletivo/amostra adequadamente definido. A probabilidade tem uma significado real apenas como probabilidade em um determinado coletivo. A base da teoria da probabilidade de Richard von Mises é, portanto, o conceito de coletivo. Um conceito racional de probabilidade, em oposição à 'probabilidade' da fala cotidiana, adquire um significado preciso somente se o coletivo ao qual ela se aplica for definido rigorosamente em cada caso. Em essência, um coletivo consiste em uma sequência de observações que pode ser continuada indefinidamente. Cada observação termina com o registro de um determinado atributo. A frequência relativa com que um atributo especificado ocorre na sequencia de observações tem um valor limitante, que permanece inalterado se uma sequencia parcial for formada a partir da sequência original por uma seleção arbitrária de lugar ou posição. ${ }^{9}$

Para lidar com tais fenômenos, obtemos por abstração ou idealização alguns conceitos matemáticos como, nesse exemplo, o conceito de coletivo matemático. Em seguida, com base na observação, estabelecemos algumas leis empíricas que são respeitadas pelos fenômenos sob estudo. Novamente, por abstração ou idealização, obtemos dessas leis empíricas os axiomas da nossa teoria matemática. Uma vez que a teoria matemática tenha sido configurada dessa forma, podemos deduzir suas consequências a partir da lógica, as quais, por sua vez, fornecem previsões e explicações de outros fenômenos observáveis.

Aplicando-se esse esquema ao caso da teoria da probabilidade, existem, segundo Richard von Mises, duas leis empíricas que são então observadas na expectativa de coletivos empíricos. A primeiro delas pode ser chamada de lei da estabilidade de frequências estatísticas (lei dos grandes números) e se refere à crescente estabilidade das frequências estatísticas,

\footnotetext{
${ }^{9}$ Sobre o conceito de coletivo, veja também Mises (1964 ${ }^{\mathrm{b}}$, p. 11-15). Conforme explicado adiante, um coletivo é um fenômeno de massa ou uma sequência ilimitada de observações que cumpre duas condições: a condição de convergência e a condição de aleatoriedade. De acordo com Richard von Mises, muitos tipos de experimentos repetitivos geram coletivos ou o fariam, de qualquer forma, caso pudessem continuar indefinidamente. A tarefa da estatística é identificar quais experimentos têm tal propriedade geradora de coletivos e evocar as distribuições de probabilidade associadas sobre a sua classe de possíveis resultados. A tarefa do cálculo da probabilidade na estatística matemática consiste em investigar se um determinado sistema de dados estatísticos forma um coletivo, ou se ele pode ser reduzido a coletivos. Tal redução fornece uma descrição condensada e sistemática dos dados estatísticos que poderá ser devidamente considerada uma "explicação" de tais dados. Veja Richard von Mises (1981, p. 222).
} 
designada por Richard von Mises como "o fenômeno primário (Urphänomen) da teoria da probabilidade." (MISES, R., 1981, p. 14 ${ }^{\text {d }}{ }^{10}$

Conforme explica Mises:

É essencial para a teoria da probabilidade o fato de que a experiência tenha demonstrado que, em um jogo de dados, assim como em todos os demais fenômenos em massa que já mencionamos, as frequências relativas de certos atributos se tornem cada vez mais estáveis à medida que aumenta o número de observações (MISES, R., 1981, p. 12).

A primeira lei dos coletivos empíricos já era muito conhecida antes de Richard von Mises. A segunda lei, todavia, é original para ele e se relaciona a uma característica decisiva de um coletivo. Tal característica do coletivo empírico é a sua falta de ordem, ou seja, sua aleatoriedade.

A engenhosa ideia de Richard von Mises é a de que devemos relacionar a aleatoriedade ao fracasso dos sistemas de jogos de azar.

Conforme ele escreveu:

Todos os autores de tais sistemas tiveram, mais cedo ou mais tarde, a triste experiência de descobrir que nenhum sistema é capaz de melhorar suas chances de vencer a longo prazo, ou seja, de afetar as frequências relativas do aparecimento de diferentes cores ou números em uma sequência selecionada a partir da sequência total do jogo (MISES, R., 1981, p. 25).

Em outras palavras, não só as frequências relativas se estabilizam em torno de valores particulares, mas estes permanecem os mesmos se nós escolhermos, de acordo com alguma regra, uma subsequência da nossa sequencia original (finita). Esta segunda lei empírica pode ser chamada de lei dos sistemas de jogos excluídos.

O próximo passo de Richard von Mises é obter os axiomas da teoria matemática via abstração (ou idealização) a partir dessas leis empíricas. O primeiro axioma pode ser facilmente obtido a partir da lei de estabilidade das frequências estatísticas:

Axioma da convergência: considerando A um atributo arbitrário de um coletivo C, obtido $m$ vezes em $n$ ensaios, então existe $\lim _{n \rightarrow \infty} m(A) / n$. A probabilidade de $A$ em $C[P(A / C)]$ é agora definida como $\lim n \rightarrow \infty m(\mathrm{~A}) / n$. Esta é a famosa definição de probabilidade como uma frequência limitante.

Uma das principais objeções a essa teoria é a de que ela é muito restrita, pois existem muitas situações importantes em que usamos probabilidade, mas em que nada semelhante a um coletivo empírico pode ser definido. Tal definição é muito restrita, em especial, no contexto da Economia. Essa era a opinião de importantes economistas como Ludwig von Mises, John Maynard Keynes e John Hicks.

10 Richard Von Mises (1981, p. 14). De fato, a expressão "estabilidade de frequências estatísticas" é de Keynes; veja Keynes (2004, p. 336). 
Não obstante, Richard von Mises considera ser essa suposta desvantagem um ponto forte a favor de sua teoria. Pode-se, de acordo com Richard von Mises, iniciar com os conceitos imprecisos da linguagem comum, substituindo-os por conceitos mais precisos quando da construção de uma teoria científica. Assim, é claro, podemos iniciar com o vago conceito de probabilidade da linguagem comum, propondo uma definição precisa para fins científicos. Tal processo é feito pela definição de probabilidade de frequência limitante, a qual exclui alguns usos do termo probabilidade da linguagem comum, para os quais um coletivo não pode ser definido, o que não é algo ruim. Pelo contrário, é certamente benéfico excluir alguns usos vagos do termo probabilidade não adequados ao tratamento matemático. Resumindo tal linha de argumentação, ele escreve:

A probabilidade de ganhar uma batalha, por exemplo, não tem lugar na nossa teoria da probabilidade, porque não podemos pensar em um coletivo ao qual ela pertença. A teoria da probabilidade não pode ser aplicada a esse problema do mesmo modo que o conceito físico de trabalho não pode ser aplicado ao cálculo do 'trabalho' feito por um ator ao recitar seu texto em uma peça de teatro (MISES, R., 1981, p. 25). ${ }^{11}$

Supõe-se que a definição de probabilidade de frequência limitante seja uma definição operacional de um conceito teórico (probabilidade) em termos de um conceito observável (frequência). Poder-se-ia alegar, entretanto, que ela deixa de fornecer uma conexão entre observação e teoria por causa do uso de limites em uma sequência infinita. É bem sabido que duas sequencias podem concordar nas primeiras $n$ posições para qualquer número finito, embora grande e, ainda assim, convergirem para limites bastante diferentes. Uma objeção semelhante diz respeito à questão de saber se é legítima a representação de um coletivo empírico finito por um coletivo matemático infinito.

A resposta de Richard von Mises a essa dificuldade é a de que tais representações do finito pelo infinito ocorrem por toda parte na física e na matemática e que o objetivo dele é somente apresentar a teoria da probabilidade de uma forma que seja tão rigorosa como o resto da física matemática. Na mecânica, por exemplo, usamos partículas pontuais para representar corpos com dimensões, linhas infinitamente finas para representar linhas com espessura finita e assim por diante. Richard von Mises argumenta que está tentando apresentar a teoria da probabilidade como uma ciência matemática tal qual a mecânica, e não é razoável esperar que ele a torne ainda mais rigorosa que a mecânica. Como ele escreveu:

Os resultados de uma teoria com base na noção do coletivo infinito podem ser aplicados a sequencias finitas de observações de forma não logicamente definível, embora se mostre suficientemente precisa na prática. A relação entre teoria e observação é, nesse caso, essencialmente a mesma que em todas as outras ciências físicas. (MISES, R. 1981, p. 85) ${ }^{12}$

\footnotetext{
${ }^{11}$ Com respeito a suas ideias positivistas, Richard von Mises foi muito influenciado por E. Mach, quem ele muito admirava. Veja Richard von Mises (MISES, R., 1981, p.25) onde ele escreve: "O ponto de vista representado neste livro corresponde essencialmente às ideias de Mach". Há referência a tal ponto também em Richard von Mises (1951, p.225).

12 A dificuldade prática surge do fato de que um coletivo é definido para uma sequência infinita. Toda coletividade é uma idealização. Estritamente falando, nenhum enunciado de probabilidade de frequência relativa diz qualquer coisa sobre qualquer evento finito ou grupo ou série de eventos. Em outras palavras, qualquer frequência calculada é perfeitamente consistente com qualquer atribuição de probabilidade de zero a um. Combinada à asserção de que não existe tal probabilidade de um evento "singular", pareceria que qualquer atribuição empírica definitiva de probabilidades numéricas seria uma quimera. Uma declaração sobre o limite de uma sequência de ensaios que seguem hipoteticamente até o infinito contém por si mesma nenhuma informação sobre qualquer segmento inicial de tal sequência. Qualquer segmento inicial de um coletivo - e, é claro, sempre seremos capazes apenas de observarmos segmentos iniciais - pode ser substituído por qualquer sequência arbitrária de mesmo comprimento, sem
} 
Para completar o programa de Richard von Mises, deve-se examinar como o segundo axioma matemático - o axioma da aleatoriedade - pode ser obtido a partir da empírica lei de sistemas de jogos de azar. Ocorre que a formulação do axioma de aleatoriedade também envolve grandes dificuldades matemáticas. Mesmo que essas fossem eventualmente superadas, os vários desenvolvimentos matemáticos sutis que proveram uma base matemática rigorosa à teoria de Richard von Mises são de pouca relevância no contexto atual. Sua ideia principal é lembrada aqui, todavia:

\subsection{Condição de aleatoriedade}

Os limites fixos aos quais tendem as frequências relativas de atributos particulares dentro de um coletivo não são afetados por nenhuma seleção de posição ou lugar, isto é, ao se escolher uma subsequência infinita cujos elementos são uma função dos resultados anteriores. Ou seja, se calcularmos a frequência relativa de algum atributo que não esteja na sequência original, mas em um conjunto parcial, selecionado de acordo com alguma regra fixa, então devemos exigir que a frequência relativa assim calculada tenda ao mesmo limite, tal qual o faz no conjunto original. A este respeito, Richard von Mises fez a seguinte estipulação:

A única condição essencial é se a pergunta 'se determinado membro da sequencia original pertence ou não à sequência parcial selecionada' deve ser feita independentemente do resultado da observação correspondente, ou seja, antes de se conhecer qualquer coisa sobre esse resultado. (MISES, R., 1981, p. 25) ${ }^{13}$

Uma importante implicação da teoria de frequência de Richard von Mises é a de que ao lidar com eventos únicos, os métodos estatísticos ou estocásticos serão essencialmente inúteis. Quando inexistem coletivos, a teoria da probabilidade e os cálculos baseados nela nada

afetar nenhum dos limites do coletivo (MISES, R., 1981, p. 85). Richard von Mises reconhece que "poderia parecer que a nossa teoria nunca poderia ser testada experimentalmente" (MISES. R., p. 84). Sua solução probabilística para este problema é pragmática. A validade empírica da teoria não depende de uma solução lógica, mas é determinada por uma decisão prática. Tal decisão deve basear-se na experiência prévia de aplicações bem-sucedidas da teoria da probabilidade, em que estudos práticos mostraram que a aproximação dos limites de frequência se dá de modo comparativamente rápido. Além disso, a idealização do coletivo é comparável a outras idealizações científicas bem-conhecidas como a determinação de um peso específico (sua medida perfeita é impossível), a existência de um ponto no espaço euclidiano ou o conceito de velocidade. A velocidade de um objeto em aceleração em dado momento no tempo é a proporção entre seu deslocamento e o tempo decorrido: $d s / d t$. Supondo que o movimento não seja uniforme, como no caso de um corpo em queda livre, cuja velocidade aumenta à medida que ele cai, para obter sua velocidade calcula-se a "taxa instantânea de variação" da distância em relação ao tempo, tomando-se o seguinte limite:

$v=\lim d s / d t$ $d t \Rightarrow 0$

É impossível verificar se existe tal limite. Não segue, todavia, que o conceito de velocidade não seja operacional. Esta crítica duplicaria a crítica da probabilidade como o limite de uma sequência, porém não seria considerada uma objeção séria, porque a definição de velocidade como um limite se provou aplicável a muitas instâncias diferentes de movimento, da mesma forma que a teoria da frequência foi aplicada de modo exitoso a muitas instâncias. Nesse último caso, a relação entre teoria e observação é essencialmente a mesma que em todas as outras ciências físicas. Lembramos aqui que a definição de Ludwig von Mises de probabilidade de classe, discutida adiante, é 'finitista' no sentido que ela dispensa inteiramente qualquer referência ao conceito de limite. Neste sentido limitado, pode-se considerar que a definição de Ludwig von Mises de probabilidade de classe constitui uma melhoria na definição de coletivo proposta por Richard von Mises.

${ }^{13}$ Conforme já indicado, o cumprimento da segunda condição (insensibilidade à seleção de posição) também é descrito por Richard von Mises como o princípio da impossibilidade de um sistema de jogos bem-sucedido (MISES, R., 1981, p. 25). 
acrescentarão ao nosso conhecimento sobre a realidade do mundo. Somente onde a experiência prévia tiver estabelecido que os eventos em questão podem ser considerados pertencentes a um coletivo poderão os métodos estatísticos desempenhar algum papel. Os cálculos das companhias de seguros, por exemplo, demonstram que os métodos estocásticos desempenham um papel legítimo em certos tipos de decisões de negócios, notadamente quando se trata de eventos pertencentes a um coletivo. A teoria da probabilidade começa com certas frequências dadas e daí deriva novas frequências por meio de cálculos realizados segundo determinadas regras estabelecidas. Em outras palavras, cada cálculo de probabilidade se baseia no conhecimento de certas frequências relativas em longas sequências de observações, e seu resultado é sempre a previsão de outra frequência relativa, que pode ser testada por uma nova sequencia de observações. A tarefa da teoria da probabilidade é, portanto, derivar novos coletivos e suas distribuições a partir de distribuições dadas em um ou mais coletivos iniciais. ${ }^{14}$

A definição de probabilidade de frequência limitante de Richard von Mises pretendeu claramente limitar o escopo da teoria matemática da probabilidade e, de fato, do conceito científico de probabilidade ${ }^{15}$. Só podemos, reivindicou ele, introduzir probabilidades em um sentido científico - o que aqui também significa - em um sentido matemático ou quantitativo - em que há um grande conjunto de eventos uniformes. Por fim, ele nos exorta a observar sua máxima: "Primeiro o coletivo - depois, a probabilidade" (MISES, R., 1981, p. 18) ${ }^{16}$.

Apesar da controvérsia, pode-se esperar que a teoria de frequência permanecerá significativa para a pesquisa nas ciências naturais. ${ }^{17}$

\footnotetext{
${ }^{14}$ A derivação de um novo coletivo a partir dos iniciais consiste na aplicação de uma ou várias das quatro operações fundamentais

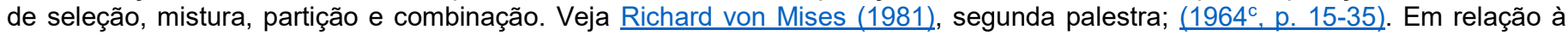
solução 'frequentista' ao problema de inferência proposto por Richard von Mises, a mesma consiste na combinação do conceito de frequência de um coletivo com o Teorema de Bayes, um resultado conhecido como 'a segunda lei dos grandes números'. A fórmula de Bayes mostra uma relação entre funções de probabilidade anteriores e posteriores. Se a distribuição prévia é conhecida, não existe problema conceitual para a aplicação do teorema de Bayes. Muitas vezes, todavia, a função de probabilidade anterior não será conhecida e, então, uma parte importante da teoria da probabilidade é a de conhecer qual influência a função de probabilidade anterior terá no cálculo da distribuição posterior. Em geral, vale o seguinte: uma inferência não substancial pode ser extraída de um pequeno número de observações se nada for conhecido a priori, isto é, algo preliminar aos experimentos e relativo ao objeto de experimentação. Se a distribuição anterior não for conhecida e o número de observações, digamos, os lançamentos de um dado, for pequeno, então a distribuição posterior não permitirá tirar conclusões com precisão. Por outro lado, um grande número de observações limita a importância de se conhecer a distribuição prévia. Enquanto o número de experimentos for pequeno, a influência da distribuição inicial predomina; contudo, à medida que o número de experimentos aumenta, tal influência diminui. Muitas vezes, a distribuição prévia não será conhecida. O agente terá então que pressupor uma distribuição, amostrar a população e, em seguida, revisar seu palpite de acordo com a fórmula de Bayes. Isto significa que as ações de um indivíduo também serão guiadas pela precisão de seu palpite.

15 Conforme escreveu ele: "Nossa teoria de probabilidade nada tem a ver com questões tais como 'há alguma probabilidade de que a Alemanha se envolva no futuro em uma guerra com a Libéria?'" (MISES, R., 1981, p. 9).

${ }^{16}$ Richard von Mises defendeu uma visão monista da probabilidade, ou seja, que existe apenas um conceito de probabilidade de importância científica; seu irmão Ludwig von Mises, por outro lado, adotou uma visão dualista da probabilidade.

17 Para um testemunho recente desse fato, veja, por exemplo, Khrennikov (1999). Este autor argumenta que certos problemas nos fundamentos da mecânica quântica - como o paradoxo de Einstein-Podolsky-Rosen - estão ligados aos fundamentos da teoria da probabilidade e, portanto, têm origem puramente matemática. Em particular, o comportamento patológico (ou não clássico) de "probabilidades quânticas" - especificamente a desigualdade de Bell - é uma consequência do uso formal do modelo de probabilidade de Kolmogorov. Esse autor usa as interpretações de conjunto e frequência como as duas interpretações fundamentais de probabilidade e chega a resultados surpreendentes. A desigualdade de Bell não pode ser usada como
} 


\section{A ABORDAGEM EPISTÊMICA DE JOHN MAYNARD KEYNES SOBRE PROBABILIDADE: A INTERPRETAÇÃO LÓGICA}

A interpretação lógica da probabilidade considera a probabilidade como tendo um grau de associação parcial. O Tratado de Keynes preocupa-se com uma teoria geral de argumentos que partem de premissas e levam a conclusões que são plausíveis, mas das quais não se têm certeza'. Considerando que 'e' seja a premissa e ' $h$ ' a conclusão de um argumento. Keynes afirma que a relação familiar de que 'e implica em h' é o caso limitante de uma relação geral (de probabilidade) de 'e implica parcialmente em h'. O objetivo de Keynes em seu Tratado é sistematizar declarações que envolvam tais relações de associações parciais. A teoria lógica usa a palavra "probabilidade" principalmente em relação à verdade de sentenças ou proposições.

Ela tem como objetivo atribuir valores verdadeiros diferentes de zero ou um para as proposições. Nesse processo, a parte de nosso conhecimento obtida diretamente fornece as premissas da parte obtida indiretamente ou por argumentação. A partir dessas premissas, procuramos justificar algum grau de crença racional sobre todos os tipos de conclusões. Assim o fazemos percebendo certas relações lógicas entre as premissas e as conclusões. $O$ tipo de crença racional que inferimos de tal maneira é denominado provável (ou no limite correto) e as relações lógicas, pela percepção das quais tal crença é obtida, denominamos relações de probabilidade ${ }^{18}$.

Comparações entre duas probabilidades são possíveis apenas quando elas e o "correto" se alinham em uma mesma série ordenada. Probabilidades que não são da mesma ordem não podem ser comparadas. Somente quando a medição numérica de probabilidades é possível, algo que é apenas ocasionalmente possível e que é, portanto, alvo de verificações especiais em cada caso, poderão então ser realizadas operações algébricas como adição e multiplicação aritmética. Os números zero (0) e um (1) figuram como os casos extremos. A

argumento para não localidade ou não realidade. Historicamente, embora tenha sido argumentado que o pano de fundo filosófico da probabilidade subjetiva esteja fortemente ligado à mecânica quântica (GALAVOTTI, 1995ª), é o 'frequentismo' que se tornou a "visão bem-recebida" da probabilidade e parece ter sido tacitamente assumido também pelos defensores da interpretação de Copenhague da mecânica quântica (embora a atribuição de probabilidades a um único caso tenha sido geralmente admitida). Nesse contexto, muitas vezes as atenções se voltaram ao ponto de vista de Heisenberg, segundo o qual "a função de probabilidade combina elementos objetivos e subjetivos e contém declarações sobre possibilidades ou tendências superiores ("potencial" na filosofia aristotélica) e estas declarações são completamente objetivas e não dependem de nenhum observador. A função de probabilidade contém declarações sobre o nosso conhecimento do sistema que são claramente subjetivas na medida em que podem ser diferentes para observadores diferentes. Nos casos ideais, o elemento subjetivo na função de probabilidade pode ser praticamente insignificante em comparação ao elemento objetivo. Os físicos se valem então da expressão "caso puro". Veja Heisenberg (1958, p. 41) e também a discussão em Galavotti (1995b).

18 Keynes normalmente adota a linha empirista de que o conhecimento adquirido por conhecimento direto constitui conhecimento certo e verdadeiro. Já o conhecimento por argumentação, em contraste, prossegue através do conhecimento das relações que assumem formas do tipo 'e implica em h' ou 'e implica parcialmente em h'. 
probabilidade zero (0) indica a impossibilidade e a probabilidade um (1) indica a verdade de uma proposição.

A ideia de uma lógica de probabilidade que devesse ser a arte do raciocínio a partir de evidências inconclusivas foi desenvolvida de forma sistemática por John Maynard Keynes, embora sugestões e indicações quanto a tal abordagem tenham sido expressas pelo menos desde Leibniz. Keynes considera a teoria da probabilidade, assim como a Economia, como ramos da Lógica. Apesar de Richard von Mises chamar Keynes de "subjetivista persistente" (MISES, R., 1981 , p. 94), Keynes deixa claro, no início de seu livro, que sua teoria é, em um sentido importante, uma teoria objetiva. Para Keynes, a probabilidade tinha um grau de crença racional e não simplesmente um grau de crença. Aquela relevante passagem vale a pena ser aqui citada em sua totalidade:

Os termos correto e provável descrevem os vários graus de crença racional sobre uma proposição que diferentes volumes de conhecimento nos autorizam a considerar. Todas as proposições ou são verdadeiras ou são falsas, mas o conhecimento que temos delas depende de nossas circunstâncias. Embora muitas vezes seja conveniente falar de proposições como corretas ou prováveis, isso expressa estritamente uma relação em que elas representam um corpus de conhecimento, real ou hipotético, porém não uma característica das proposições em si mesmas. Uma proposição é capaz de figurar ao mesmo tempo em graus variados dessa relação, dependendo do conhecimento ao qual ela está relacionada, de modo que não faz sentido chamar uma proposição de provável, a menos que especifiquemos o conhecimento ao qual a estamos relacionando. Nesse contexto, portanto, a probabilidade pode ser chamada de subjetiva. Todavia, no sentido que importa para a lógica, a probabilidade não é subjetiva, pois ela não está, digamos, sujeita ao capricho humano. Uma proposição não é provável porque 'achamos' que seja. Pois, tão logo existam fatos que determinem nosso conhecimento, o que é provável ou improvável em tais circunstâncias terá sido objetivamente fixado, isto é, independe de nossa opinião. A Teoria de Probabilidade é lógica, portanto, porque diz respeito ao grau de crença que é racional entreter em determinadas condições e não meramente às crenças reais de indivíduos específicos, que podem ou não ser racionais. (KEYNES, 2004, p. 3-4a) ${ }^{19}$

É importante reconhecer, ponto a ponto, a discordância existente entre as teorias de Richard von Mises e John Maynard Keynes ${ }^{20}$. Para Richard von Mises, a probabilidade é um ramo da ciência empírica. Para Keynes, ela é uma extensão da lógica dedutiva; Von Mises definiu a probabilidade como uma frequência limitante, já Keynes como um grau de crença racional; Para von Mises, os axiomas da probabilidade são obtidos por abstração a partir de duas leis empíricas; para Keynes, eles são obtidos por intuição lógica direta. Em um desses pontos parece haver algum acordo. Nenhum deles pensa que todas as probabilidades têm um valor numérico, porém as posições dos dois autores com relação a tal fato são muito diferentes. Para Richard von Mises, somente as probabilidades definidas dentro de um coletivo empírico podem ser avaliadas, e

\footnotetext{
19 É amplamente aceito que Keynes cedeu aos argumentos críticos de Ramsey (1988) e abandonou a ideia de que as crenças racionais baseiam-se em relações lógicas de implicação parcial, passando a aceitar que elas estão mais próximas de nossas percepções e memórias do que da lógica formal. Como diz Runde (1994), a teoria da probabilidade comparativa de Keynes permanece incólume. Por um lado, a teoria de Ramsey incorpora fortes pressupostos implícitos próprios e, em certos aspectos, é uma construção consideravelmente mais idealista que a de Keynes. Por outro, a ênfase de Keynes é na incompletude e no fato de que as probabilidades numericamente definidas só podem ser determinadas em situações que se aproximam aos jogos de azar (KEYNES, 2004, p. 3-4).

20 Veja também Gillies (1973, p. 14-15).
} 
somente elas despertam qualquer interesse para a ciência. Para ele, os outros usos da probabilidade são exemplos de um conceito bruto pré-científico, e merecem apenas desprezo. Para Keynes, por outro lado, todas as probabilidades estão essencialmente no mesmo nível. Todas obedecem as mesmas regras formais e desempenham o mesmo papel em nosso pensamento. Certas características especiais da situação nos permitem atribuir-Ihes valores numéricos em alguns casos, mas não em todos. Através do reconhecimento de que a probabilidade de frequência não abrange tudo o que queremos dizer com 'probabilidade', a posição de Keynes é também mais próxima daquela adotada por economistas como Ludwig von Mises e John Hicks. Em suma, a posição da estatística difere nas duas abordagens. Para von Mises, trata-se do estudo de como aplicar a teoria da probabilidade na prática, como ocorre na mecânica aplicada. Para Keynes, a inferência estatística é um tipo especial de inferência indutiva e a estatística é um ramo da teoria da indução.

Portanto, as diferenças mais marcantes entre John Maynard Keynes e Richard von Mises são:

- De acordo com Richard von Mises, a teoria da probabilidade pertence às ciências empíricas, com base em frequências limitantes, enquanto Keynes a considera um ramo da lógica, com base em graus de crença racional; e

- Os axiomas de Richard von Mises são idealizações de leis empíricas, já os axiomas de Keynes seguem da intuição da lógica.

É fato bastante notável que o significado prático dessas diferenças de princípios não impeça os dois autores de estarem praticamente de acordo sobre quase todos os teoremas matemáticos de probabilidade, bem como sobre os campos potencialmente exitosos de aplicação da estatística. Assim, o total desacordo entre eles em todas as questões filosóficas é acompanhado por total acordo em relação ao lado matemático. Além disso, outra conclusão essencialmente similar pode ser tirada no que diz respeito ao escopo potencial de uma aplicação bem-sucedida de conceitos de probabilidade numérica.

Assim, na Parte V do Tratado, no contexto de sua discussão sobre inferência estatística, Keynes tem o grande mérito de perceber que a aplicabilidade de algumas das partes essenciais da doutrina clássica assume independência ou irrelevância. ${ }^{21}$

${ }^{21}$ Conforme escreve Keynes: "Supõe-se, em primeiro lugar, que o conhecimento daquilo que ocorreu em alguns dos ensaios não afetaria a probabilidade do que poderia ocorrer em qualquer um dos demais; presume-se, em segundo lugar, que essas probabilidades são todas iguais a priori. Presume-se assim que a probabilidade de ocorrência do evento no ensaio ' $r$ ' é igual a priori à sua probabilidade no ensaio ' $n$ ' e, ademais, que não seja afetada por um conhecimento do que pode, na verdade, ter 
Keynes também sugeriu renomear a lei dos grandes números para lei da estabilidade das frequências estatísticas, a qual fornece um claro resumo do seu significado:

Mas a 'lei dos grandes números' não é um bom nome para o princípio subjacente à indução estatística. A 'Estabilidade das Frequências Estatísticas' seria um nome muito melhor para ela. O primeiro sugere, como talvez Poisson quisesse sugerir, embora seja certamente falso, que toda classe de evento mostra uma regularidade estatística de ocorrência, apenas se considerarmos um número suficiente de instâncias. Ele também incentiva o método de procedimento, pelo qual se considera legítimo tomar qualquer grau observado de frequência ou associação, o que é mostrado em um conjunto bastante numeroso de estatísticas, supondo com investigação insuficiente, que só porque as estatísticas são numerosas, o grau de frequência observado seria, portanto, estável. A observação mostra que algumas frequências estatísticas são estáveis dentro de limites mais estreitos ou mais amplos, mas as frequências estáveis não são muito comuns e não podem ser presumidas de forma leviana. (KEYNES, 2004, p. 336 b)

De acordo com o ponto de vista da frequência, a aplicação bem-sucedida de teoria da probabilidade, em especial, para fins de inferência estatística, está condicionada ao cumprimento de um pressuposto particular: em um domínio particular da realidade, um ou mais coletivos existem como uma questão de fato. Isto significa que aplicações adequadas das leis dos grandes números dependem de uma suposição de homogeneidade em relação ao fenômenos submetidos a estudo.

Vale salientar que Keynes, ao examinar a validade e as condições de aplicabilidade do teorema de Bernoulli e sua inversão, chega a conclusões semelhantes.

Conforme escreveu ele:

Se soubéssemos que nosso mundo material poderia ser comparado a um jogo de azar, poderíamos esperar inferir chances a partir de frequências, com o mesmo tipo de confiança com a qual inferimos frequências a partir de chances. (KEYNES, 2004, p. 384-5c ${ }^{22}$

Tais ressalvas são similares às de vários economistas austríacos. Por exemplo, Ludwig von Mises claramente duvida que a empírica lei de estabilidade de frequências estatísticas seja operacional na realidade social:

Entretanto, o que as estatísticas das ações humanas realmente mostram não é regularidade, mas irregularidade. O número de crimes, suicídios e atos de esquecimento varia anualmente. Essas mudanças anuais são, no geral, pequenas, porém, após um período de anos, muitas vezes - embora não sempre - mostram uma tendência definitiva para aumentarem ou diminuírem. Tais estatísticas são indicativas de mudanças históricas, não de regularidade no sentido vinculado a este termo pelas ciências naturais. (MISES, L., 1969 , p. $84-5)^{23}$

ocorrido no ensaio 'n'. "(KEYNES, 2004, p. 344). Conforme ressaltou Karl Popper, a teoria da independência ou irrelevância é, portanto, equivalente à lei dos sistemas dos jogos excluídos (POPPER, 1983, p. 299b).

22 Significativamente, Keynes também escreveu o seguinte em relação à aplicação da fórmula de Bernoulli: "Nos casos em que o uso dessa fórmula é válido, pode-se delinear inferências importantes. Será demonstrado que, quando as condições para uma chance [possibilidade de ocorrência] objetiva são satisfeitas de modo aproximado, é provável que as condições para a aplicação da fórmula de Bernoulli também sejam satisfeitas de modo aproximado" (KEYNES, 2004, p. 384-5; p. 290).

${ }^{23}$ Veja L. Mises (1969 [1957], p. 84-5; 2014, p. 56ª ) onde Mises escreveu: "não existem leis estatísticas". Segundo tal ponto de vista, a estatística estaria mais para uma subdisciplina ou uma disciplina auxiliar da historiografia. 


\section{RICHARD VON MISES VERSUS LUDWIG VON MISES EM RELAÇÃO À PROBABILIDADE}

Apresentamos nesta seção um amplo volume de evidências extraídas dos escritos de Ludwig von Mises que são difíceis de harmonizar com a tese de que Ludwig von Mises adotou basicamente a interpretação de frequência de probabilidade de seu irmão Richard von Mises.

É notável que algumas das declarações mais reveladoras de Ludwig von Mises sobre a natureza e o significado do conceito de probabilidade se relacionem a um contexto que é alheio à ciência econômica em si. Se há um campo de investigação científica em que a natureza e a interpretação do cálculo de probabilidade tenha sido objeto de debate, é o domínio da mecânica quântica e da filosofia da mecânica quântica. Já observamos ao final da Seção III que, apesar da controvérsia, a interpretação de frequência continua a ser altamente significativa para a condução das ciências naturais. Voltamos aqui nossa atenção especificamente à comparação do conceito de probabilidade de classe de Ludwig von Mises com o conceito de probabilidade de frequência de Richard von Mises.

Os escritos de Ludwig von Mises contêm muitos insights importantes sobre a filosofia das ciências e não é de se surpreender que ele tivesse uma opinião franca sobre a questão. $\mathrm{Na}$ obra Teoria e História, na seção intitulada Determinismo e Estatísticas, ele expressou sua visão em relação à mecânica quântica do seguinte modo:

A mecânica quântica lida com o fato de que não sabemos como um átomo se comportará em determinado caso. Mas sabemos que padrões de comportamento têm a possibilidade de ocorrer, e a proporção em que de fato ocorrem estes padrões. Embora a forma perfeita de uma lei causal seja: A "produz" B, também existe uma forma menos perfeita: A "produz" $\mathrm{C}$ em $\mathrm{n} \%$ de todos os casos, $\mathrm{D}$ em $\mathrm{m} \%$ de todos os casos, e assim por diante. Talvez algum dia seja possível dissolver este A da forma menos perfeita em diversos outros elementos distintos, para cada qual será atribuído um "efeito" específico de acordo com a forma perfeita. Mas se isto acontecerá ou não é algo irrelevante para o problema do determinismo. A lei imperfeita também é uma lei causal, embora ela revele falhas em nosso conhecimento. E exatamente por ela ser uma demonstração de um tipo peculiar tanto de conhecimento quanto de ignorância, ela abre caminho para a utilização do cálculo de probabilidade. (MISES, L., 2014, p. 76 ${ }^{\mathrm{b}}$ )

Então, Mises fornece a famosa definição de seu conceito da probabilidade de classe:

Sabemos, no que diz respeito a um problema específico, tudo sobre o comportamento de
toda uma classe de eventos; sabemos que a categoria A produzirá efeitos específicos numa
proporção conhecida; mas tudo o que sabemos a respeito dos A's individuais é que eles
pertencem à classe A. A formulação matemática desta mistura de conhecimento e
ignorância é: conhecemos a probabilidade dos diversos efeitos que podem ser
possivelmente "produzidos" por um A individual. (MISES, L., 2014, p. $76^{c}$ )

Vale notar que Ludwig von Mises também é explicitamente crítico em relação à dominante interpretação não-determinista ["indeterminista"] da mecânica quântica:

O que a escola neoindeterminista de física não consegue enxergar é que a proposição "A produz B em n\% dos casos e C no resto dos casos" não é diferente, epistemologicamente, da proposição "A sempre produz B". A primeira difere da segunda apenas por combinar em 
sua noção de $A$ dois elementos, $\mathrm{X}$ e $\mathrm{Y}$, que a forma perfeita de uma lei causal teria que distinguir. Mas nenhuma questão de contingência foi levantada. (MISES, L., 2014, p. 76d)

Na obra Ação Humana, Ludwig von Mises manifestou preocupação semelhante:

O tratamento dado ao problema da causalidade nas últimas décadas foi bastante insatisfatório, graças à confusão provocada por alguns físicos eminentes. Existem mudanças cujas causas são desconhecidas para nós, pelo menos no momento atual. Algumas vezes conseguimos adquirir um conhecimento parcial que nos permite afirmar: em $70 \%$ de todos os casos, resulta $A$ em $B$; nos casos remanescentes, resulta em $C$, ou mesmo em $D, E, F$ e assim por diante. A fim de substituir esta informação fragmentada por informação mais precisa, seria necessário decompor $A$ em seus componentes. Enquanto isto não for conseguido, temos de aquiescer com o que é conhecido como lei estatística. (MISES, L., 2010a , p. 48)

Essas passagens são importantes e interessantes porque ilustram claramente o fato de que no contexto do conhecido debate histórico entre físicos - estando, de um lado, os que acreditavam que a mecânica quântica era incompleta e que estavam tentados a aceitar que "Deus não joga dados" e, de outro, os que acreditavam que as leis fundamentais da natureza seriam irredutivelmente probabilistas - Ludwig von Mises toma partido dos primeiros ${ }^{24 ; 25}$. Ludwig von Mises claramente associa o uso do cálculo de probabilidade ao conhecimento parcial, ou seja, à ignorância e às imperfeições do nosso conhecimento, e não à existência de qualquer contingência 'in re' [em si]. Similarmente, Einstein acreditava, desde o início, que a teoria quântica carecia de alguns ingredientes-chave e que, em um sentido mais amplo, era "incompleta". Ele a comparou com a teoria da luz antes do surgimento dos quanta de luz. A teoria quântica, ele acreditava, talvez fosse uma "teoria correta das leis estatísticas", mas fornecia "uma concepção inadequada de processos elementares individuais"26.

Assim, o conceito de probabilidade de classe de Ludwig von Mises, em contraposição ao conceito de frequência de seu irmão Richard von Mises, contém uma referência à deficiência do nosso conhecimento, ou seja, à ideia de que qualquer atribuição de probabilidade descreve

\footnotetext{
${ }^{24} \mathrm{Na}$ obra The Ultimate Foundation of Economic Science, Ludwig von Mises escreveu: "Sempre haverá algo tido como derradeiro, definitivo e irrevogável na ciência. Para a física contemporânea, o comportamento dos átomos parece ser algo do tipo. Contudo, os físicos de hoje correm o risco de tentar reduzir certos processos atômicos às suas causas. Todavia, as maravilhosas realizações da Física não serão prejudicadas quando se estabelece o fato de que esse estado de coisas é aquilo que é comumente chamado de ignorância "(1978a , p. 23).

${ }^{25} \mathrm{Em}$ suma, a teoria quântica é irredutivelmente probabilística. Ao contrário das probabilidades clássicas, as probabilidades quânticas não refletem a nossa ignorância dos detalhes complexos de alguma realidade física subjacente. Einstein não gostou particularmente do elemento 'chance', implícito na teoria quântica. Em uma carta a Max Born, datada de 4 de dezembro de 1926, ele escreveu: "A mecânica quântica é muito impressionante, mas uma voz interior me diz que ela ainda não é a coisa verdadeira. A teoria traz uma boa proposta, mas dificilmente nos aproxima do segredo d'O Antigo. Estou convencido, em todas as instâncias, de que Ele não joga dados" (BAGGOT, 2004, p. 34). Também se pode fazer referência nesse contexto ao confronto entre Einstein e Bohr sobre a interpretação da teoria quântica e dos debates subsequentes em linhas semelhantes e que muitas vezes foram retratados no passado como um conflito direto entre realismo e positivismo. Para discussão sobre tais questões, veja Baggott (2004). O problema para Einstein parece ter sido mais a questão do realismo que a do determinismo. Ludwig von Mises está aparentemente do lado realista. Para uma análise sofisticada dos pontos de vista de Einstein a este respeito, veja também Fine $\left(1986^{a}\right)$. A observação de Einstein sobre Deus jogando dados ("...ob der liebe Gott würfelt") também é citada em Bohr (1949, p. 218). Veja também Fine $\left(1986^{b}\right.$, p. 29)

${ }^{26}$ Carta de Albert Einstein a Arnold Sommerfeld, datada de 9 de novembro de 1927 (FINE, 1986c , p. 29).
} 
apenas um estado de conhecimento. Uma declaração é provável se o nosso conhecimento sobre o seu conteúdo é deficiente (MISES, L., 2010 ${ }^{\text {, }}$ p. 52). De acordo com este ponto de vista, o uso de leis estatísticas sinaliza conhecimento parcial e informação fragmentada. Inexistem leis estatísticas em um sentido físico objetivo.

Como nos lembra Popper, a visão amplamente aceita de que, sempre que a probabilidade entra em nossas considerações é devido ao nosso conhecimento imperfeito, é um resquício das interpretações subjetivas do cálculo de probabilidade (POPPER, 1983, P. 295ª). A interpretação de frequência objetiva não tem tal conotação.

De acordo com a opinião geral sobre esse assunto, (quase todas) as probabilidades que aparecem na mecânica quântica teórica são, de fato, probabilidades objetivas, ou seja, inerentes ao mundo, e não mero reflexo dos graus de crença ou de conhecimento de um observador (HUGHES, 1992, p. 218) ${ }^{27}$.

Estas observações são suficientes para estabelecer o fato de que a interpretação de Ludwig von Mises sobre a lei dos grandes números, em particular, sua interpretação do conceito de probabilidade de classe, é fundamentalmente distinta da interpretação de seu irmão Richard von Mises. Com efeito, segundo Richard von Mises, a visão de que as teorias estatísticas são apenas explicações temporárias, em contraste com as explicações determinísticas finais que, por si só, satisfazem o nosso desejo por causalidade, nada mais é que um preconceito fadado a desaparecer à medida que obtemos maior compreensão do tema (MISES, R., 1981 p. 223$)^{28}$.

O contraste entre as opiniões de Ludwig von Mises e de Richard von Mises a este respeito também pode estar relacionado ao fato que a visão de mundo de Ludwig von Mises, em contraposição à de seu irmão Richard von Mises, exibiu, aparentemente, alguma inclinação para o determinismo metafísico ${ }^{29}$.

\footnotetext{
27 As possíveis exceções ocorrem quando um sistema encontra-se em estado misto. Sob a interpretação de ignorância de uma determinada mistura, uma probabilidade subjetiva é atribuída a cada um dos estados puros nela representados e cada um destes, por sua vez, atribui probabilidades objetivas aos eventos. Entretanto, nem todas as misturas podem receber a interpretação da ignorância. Para uma discussão de estados puros e mistos, vide também van Fraassen (1991, cap. 7). A interpretação dos estados quânticos é uma questão de muito debate. Para discussões aprofundadas sobre estes assuntos e outros a eles relacionados, veja especialmente Willem M. de Muynck (2002).

${ }^{28}$ Conforme escreve Richard von Mises: "O pressuposto de que uma teoria estatística na macrofísica é compatível com uma teoria determinística na microfísica é contrária à concepção de probabilidade expressa nessas palestras. A mecânica quântica ou mecânica ondulatória parece ser uma teoria puramente estatística; suas equações fundamentais indicam relações entre distribuições de probabilidade" (MISES, R., 1981, p. 223). A incompatibilidade com as opiniões expressas por seu irmão Ludwig Von Mises não pode ser mais clara. Portanto, não compartilhamos da visão de um autor que explica a ausência de qualquer menção na obra Ação Humana de Ludwig de von Mises à interpretação de frequência de Richard von Mises com referência a um suposto "distanciamento" entre os dois irmãos. Claramente, havia uma discordância filosófica entre os dois irmãos. Veja Hoppe $\left(2006^{\text {b }}\right.$, p. 13).

${ }^{29}$ Veja, por exemplo, Ludwig von Mises $\left(1978^{b}\right.$, p. 115). Voltando à mecânica quântica, pode-se notar que o físico americano David Bohm formulou na década de 1950 uma interpretação alternativa da mecânica quântica totalmente determinista (embora não local). A própria ideia de probabilidade entra nessa teoria como algum tipo de ideia epistêmica, tal qual o faz na mecânica estatística clássica. Apesar de todas as vantagens da teoria de Bohm, há uma recusa quase universal até mesmo em considerá-la e, ao mesmo tempo, uma fidelidade quase universal à formulação padrão da mecânica quântica, que persistiu na Física durante a maior parte dos últimos 50 anos. Para uma introdução resumida à abordagem de Bohm, veja Albert (1994).
} 
É verdade que o contraste entre o conceito de probabilidade de classe de Ludwig von Mises e a noção de coletivo de Richard von Mises permanece, de certa forma, oculto e, portanto, corre o risco de passar despercebido devido ao fato que, em algumas ocasiões, Ludwig von Mises usa uma terminologia que remonta à ideia de "frequência".

Na obra Ação Humana, por exemplo, Ludwig von Mises, de modo explícito e inequívoco, caracteriza a noção de probabilidade de classe como variante da probabilidade de frequência (MISES, L., 2010, p. 107). Todavia, essa questão terminológica não pode invalidar nossa tese de que, tudo considerado, a filosofia de probabilidade de Ludwig von Mises tem mais afinidade com uma visão epistemológica (epistêmica) - como a teoria lógica de Keynes - que com a visão de frequência de seu irmão Richard von Mises.

A conclusão a que chegamos é, portanto, cheia de nuances. Por um lado, Ludwig von Mises relaciona claramente a ideia de probabilidade ao estado de conhecimento do assunto conhecido pelo indivíduo. Isto é verdade tanto para a probabilidade de classe quanto para a probabilidade de caso. Uma declaração é provável se nosso conhecimento sobre o seu conteúdo for deficiente. Tal visão é compartilhada por todos os adeptos de uma interpretação epistemológica do conceito de probabilidade, incluindo John Maynard Keynes. Richard von Mises, ao contrário, rejeita explicitamente a ideia de que o conceito de probabilidade se refere a um estado de conhecimento parcial ou deficiente. Por outro lado, Ludwig von Mises claramente reconhece que o significado de probabilidade é diferente em função do campo de conhecimento em que ele é usado, ou de acordo com os tipos de fenômenos aos quais ele é aplicado. Assim, ele adota uma visão dualista da filosofia da probabilidade ${ }^{30}$. Nesse sentido, todavia, sua visão é, mais uma vez, claramente distinta e oposta àquela de seu irmão Richard von Mises, o qual adota uma teoria monista de probabilidade.

Além disso, da perspectiva da teoria lógica da probabilidade, o conceito de probabilidade às vezes se refere à frequência relativa. Os adeptos contemporâneos da ideia da teoria da probabilidade por inferência têm plena confiança de que sua abordagem pode abarcar os métodos frequentistas, mas apenas como uma única aplicação especializada da teoria da probabilidade (JAYNES, 2003a).

Aparentemente, essa também foi a opinião de Keynes, já que ele escreveu que "a teoria deste Tratado é a teoria generalizada, abrangendo em si tais aplicações da ideia de verdade estatística - a frequência como tendo validade" (KEYNES, 1921, p. 104 $\left.{ }^{\mathrm{d}}\right)$.

\footnotetext{
30 Portanto, a probabilidade às vezes envolve uma referência à noção de frequência relativa, mas a frequência relativa não é a característica definidora geral do conceito científico de probabilidade de acordo com Ludwig von Mises.
} 
Em outras palavras, nessa visão os problemas que podem ser resolvidos pela teoria de probabilidade de frequência formam uma subclasse daqueles que são compatíveis com a probabilidade enquanto lógica; a teoria da probabilidade enquanto lógica, todavia, também pode ser aplicada de forma consistente a muitos problemas que não se encaixam nas pré-concepções freqüentistas.

Seria prematuro concluir que tais preocupações sobre o significado da probabilidade, como as levantadas por Ludwig von Mises, sejam hoje obsoletas e, de forma inequívoca, pertençam à história da filosofia da probabilidade. Conforme um adepto da interpretação lógica da probabilidade explicou recentemente:

As probabilidades na teoria quântica atual expressam a incompletude do conhecimento humano tão verdadeiramente quanto aquelas da mecânica estatística clássica; apenas sua origem é diferente. Na mecânica estatística clássica, as distribuições de probabilidade representavam nossa ignorância das coordenadas microscópicas verdadeiras - ignorância que era evitável em princípio, mas inevitável na prática. Isso não nos impede, todavia, de prever fenômenos reprodutíveis, apenas porque tais fenômenos são independentes dos detalhes microscópicos. $\mathrm{Na}$ teoria quântica atual, as probabilidades expressam nossa ignorância devido ao nosso insucesso em buscar as causas reais dos fenômenos físicos; pior ainda, nosso fracasso em mesmo pensar seriamente sobre o problema. Tal ignorância pode ser inevitável na prática, mas em nosso atual estado de conhecimento, não sei se ela é inevitável em princípio; o 'dogma central' simplesmente defende isso e conclui que a crença nas causas, e a busca por elas, são filosoficamente ingênuas. Se todos aceitassem e se conformassem com isso, nenhum avanço posterior na compreensão das leis físicas jamais teria sido realizado; de fato, nenhum avanço foi realizado desde o Congresso Solvay em 1927, durante o qual esse tipo de mentalidade se solidificou na Física. Parece-nos, todavia, que tal atitude premia a estupidez; não ter a criatividade de pensar em uma explicação física racional significa apoiar uma visão sobrenatural. (JAYNES, 2003, p. 328$\underline{\left.g^{b}\right)^{31}}$

Mais uma vez, a discordância sobre o significado da probabilidade a nível filosófico não deve excluir um consenso aproximado quanto ao alcance legítimo da aplicação da teoria dos grandes números. É certamente duvidoso se o critério de convergência e as condições para a disponibilidade de um coletivo sempre serão satisfeitos em aplicações econômicas ou econométricas. As probabilidades na economia não são do mesmo das entidades físicas que Richard von Mises parece ter tido em mente na construção de sua teoria.

Nesse sentido, o fundamento empírico para a probabilidade, ou seja, para a probabilidade de frequência objetiva, estará tipicamente faltando. O próprio Richard von Mises parece ter sugerido que a concepção frequentista não é aplicável às ciências morais, devido à ausência de eventos que atendam às condições de um coletivo. Em suas palavras: "A extensão ilimitada da validade das ciências exatas foi uma faceta característica do racionalismo exagerado do século XVIII. Não pretendemos cometer o mesmo erro" (MISES, R., 1981, p. 9).

\footnotetext{
${ }^{31} \mathrm{Em}$ particular, as opiniões do autor se opõem totalmente às de Popper. Em relação à situação na Física, Popper, que defende a compatibilidade do indeterminismo com o realismo e o objetivismo, foi mais longe e chegou a culpar a interpretação determinista da física clássica (ou melhor, o que ele caracteriza como algum preconceito determinista inconsistente em relação à física clássica) pela teoria subjetiva da probabilidade e sua consequência - a invasão do misticismo e do irracionalismo no campo da Física (JAYNES, 2003ㄷ). Veja também Popper (1982).
} 
Nesse ponto, Ludwig von Mises e Richard von Mises parecem ter concordado.

\section{MAIS SOBRE LUDWIG VON MISES E JOHN MAYNARD KEYNES EM RELAÇÃO À PROBABILIDADE}

Já demos atenção ao fato de que tanto Ludwig von Mises como John Maynard Keynes adotaram uma interpretação mais epistemológica (epistêmica) que objetiva das probabilidades. Ambos os autores também apontam para certos limites da aplicabilidade da probabilidade numérica e, em particular, das leis dos grandes números. As respectivas opiniões destes autores sobre probabilidade têm outra importante característica em comum. Ambos reconhecem a legitimidade epistemológica e científica das probabilidades qualitativas não mensuráveis.

Com relação à questão de saber se uma medida numérica das probabilidades seria sempre possível, John Maynard Keynes criticou a tendência de interpretar probabilidades como sendo, em geral, numericamente mensuráveis. Assim escreveu ele:

A atenção (desproporcional à sua real importância) que foi dada (devido às oportunidades de manipulação matemática que elas oferecem) à classe limitada de probabilidades numéricas parece ser uma explicação parcial da crença (sendo o principal objetivo deste capítulo provar que tal crença está errada) que todas as probabilidades devem pertencer à referida classe limitada. (KEYNES, 2004, p. 37)

Seguindo a mesma linha, Ludwig von Mises escreveu:

O problema da inferência provável é muito maior do que aqueles problemas que constituem o campo do cálculo de probabilidade. Apenas tal preocupação com o tratamento matemático poderia resultar no preconceito de que a probabilidade sempre significaria frequência. (MISES, L., 2010 , p. 144)

Ludwig von Mises, que distingue entre dois tipos de probabilidade - a probabilidade de classe, que em geral corresponde à probabilidade de frequência, e a probabilidade de caso concedeu ao segundo significado de probabilidade status científico importante.

Nas palavras de Ludwig von Mises: "Probabilidade de caso significa: conhecemos alguns dos fatores que determinam o resultado de um evento; mas existem outros fatores que também podem influenciar o resultado e sobre os quais nada sabemos" (MISES, L., 2010 , p. 144).

Aqui também, contudo, a ideia de probabilidade se relaciona à ideia geral de conhecimento parcial ou imperfeito; a este respeito e apenas a este respeito, a probabilidade do caso é de fato semelhante à probabilidade de classe: "Probabilidade de caso só tem em comum, com a probabilidade de classe, a deficiência de nosso conhecimento. Em todos os outros 
aspectos, estas duas formas de probabilidade são completamente diferentes" (MISES, L., 2010. p. 144).

Embora não adotasse os termos probabilidade de caso e de classe, Keynes acreditava, como Ludwig von Mises, que a probabilidade de frequência não abrangia tudo o que queremos dizer com probabilidade. Claramente, a definição de probabilidade de frequência aleatória é muito estreita para englobar o que queremos dizer quando usamos o termo probabilidade. Dizemos, de fato, com respeito a eventos únicos que eles são mais ou menos prováveis. Muitas decisões tomadas diariamente pelas pessoas se baseiam em declarações de probabilidade que não possuem interpretação de frequência.

No capítulo 8 da obra Tratado sobre probabilidade, ao discutir a elaboração de Venn sobre a teoria de frequência, ele escreveu:

Não é só óbvia, mas também correta a crítica dessa teoria que a identificação da probabilidade com a frequência estatística é um distanciamento muito grave do uso estabelecido dos termos; pois ela claramente exclui um grande número de julgamentos, os quais geralmente acreditamos tenham como objeto a probabilidade. (KEYNES, 2004, p. 95)

Embora a teoria de frequência da probabilidade esteja relacionada a um grau de probabilidade cardinalmente mensurável, a probabilidade de caso se abre a qualquer tipo de avaliação numérica segundo Ludwig von Mises (KEYNES, 2004, p. 95).

De acordo com tal visão, a probabilidade de caso se concentra em eventos individuais que - via de regra - não fazem parte de uma sequencia. Já a probabilidade do caso não é mensurável em qualquer sentido além do ordinal; não há medida cardinal de probabilidade de caso.

O que é normalmente considerado uma avaliação numérica de probabilidade de caso, Mises argumenta, quando mais examinado mais de perto, exibe um caráter diferente - como aquele de uma metáfora (MISES, L., 2010) ${ }^{32}$. Quando seguimos para uma avaliação numérica da probabilidade de caso, isto equivale a uma tentativa de elucidar um complexo estado de coisas recorrendo a uma analogia emprestada do cálculo de probabilidade. O fato é que essa disciplina matemática é mais popular do que a análise da natureza epistemológica da compreensão. Conforme mencionamos, uma característica particular da visão de Keynes também é a de que nem todas as probabilidades são numericamente mensuráveis e, em muitos casos, sequer podem ser classificadas numa escala ordinal. ${ }^{33}$

\footnotetext{
32 Veja Ludwig von Mises (2010, p. 114). A visão de Ludwig von Mises sobre essa questão é, portanto, distinta da visão de bayesianos como Howson e Urbach, que argumentam que as escolhas dos quocientes razoáveis para apostas pessoais podem fornecer uma base para avaliações numéricas da incerteza (HOWSON; URBACH, 2006, p.51).

${ }^{33} \mathrm{Em}$ sua obra Tratado, Keynes ilustra esse ponto com o famoso exemplo do "concurso de beleza" (2004, p.25). Keynes explica como uma das candidatas do concurso processou os organizadores do Daily Express por não ter tido uma oportunidade razoável para competir. Os leitores do jornal decidiram parte das indicações. A decisão final dependia de um especialista, que teve que
} 
A este respeito, as visões de Keynes sobre a aplicabilidade das estatísticas de grandes números a proposições singulares são semelhantes às defendidas por Ludwig von Mises. Keynes foi claro sobre o porquê de se poder adotar julgamentos de probabilidade de caso mesmo quando estatísticas de grandes números estão disponíveis: "Ademais, em alguns casos, quando estatísticas gerais estão disponíveis, a probabilidade numérica que poderia delas ser derivada é inaplicável devido à presença de conhecimentos adicionais com relação àquele caso particular" (KEYNES, 2004, p. 29). ${ }^{34}$

\section{A DISTINTIVIDADE DA POSIÇÃO DE LUDWIG VON MISES NA FILOSOFIA DA PROBABILIDADE}

Apesar de certas semelhanças entre as respectivas posições de Ludwig Von Mises e John Maynard Keynes na filosofia da probabilidade, não podemos nos esquecer do fato de que suas respectivas opiniões também exibem algumas diferenças importantes. A mais importante delas está relacionada ao fato de que Ludwig Von Mises defende uma visão pluralista - e dualista - da probabilidade. De acordo com uma visão pluralista da probabilidade, existem várias noções diferentes - embora possivelmente interligadas - de probabilidade, as quais se aplicam a diferentes contextos ou em relação a diferentes tipos de fenômenos. A posição dualista de Ludwig von Mises na filosofia da probabilidade é um aspecto de seu dualismo metodológico mais geral, que se baseia no reconhecimento de certas diferenças fundamentais, ontológicas, epistemológicas e metodológicas entre as ciências naturais, por um lado, e as ciências da ação humana, por outro, assim como entre as naturezas de seus respectivos objetos de estudo. Além disso, no caso particular de Ludwig von Mises, seu dualismo na filosofia da probabilidade coincide com a distinção entre a probabilidade mensurável e numérica, por um lado, e a probabilidade não mensurável e não numérica, por outro, ou seja, coincide com a própria distinção entre a probabilidade de classe e a probabilidade de caso. ${ }^{35 ; 36}$

amostrar dentre as cinquenta primeiras-damas escolhidas pelos leitores. A candidata prestou queixa perante o Tribunal de Justiça por não ter tido a oportunidade de fazer uma entrevista com o referido especialista. Keynes argumenta que a chance de vencer o concurso poderia ter sido medida numericamente, apenas se a resposta dos leitores (que enviaram suas avaliações e, portanto, forneceram uma inequívoca classificação das candidatas) tivesse tido importância. O gosto subjetivo do único especialista não pôde ser avaliado de forma semelhante. Faltou, portanto, uma base racional para avaliar as chances da desafortunada dama. Keynes conclui: "Seja ou não uma coisa teoricamente concebível, nenhum tipo de julgamento prático é possível, pelo qual um valor numérico pode ser conferido à probabilidade de cada argumento. Longe de sermos capazes de medi-las, não fica nem mesmo claro se seríamos sempre capazes de posicioná-las em uma ordem de grandeza. Ademais, nenhuma regra teórica para tal avaliação foi sugerida até hoje" (2004, p. 27 - 8).

34 Veja Keynes (2004, p. 29). Em linha similar, Hoppe (2006 $)$, ao analisar o significado do conceito de probabilidade de caso de Ludwig von Mises, afirma que o método de Verstehen pode ser caracterizado como um método de seleção de posição ou de individualização.

${ }^{35}$ Não é o caso que, de acordo com a visão dualista da probabilidade de Ludwig von Mises, os diferentes conceitos de probabilidade sejam concebidos como diferentes interpretações do mesmo cálculo matemático, ou como aplicações do mesmo 
A solução de Ludwig von Mises para o problema de definir o conceito de probabilidade permanece - nada menos do que a de Keynes - original e altamente relevante. Onde outros invocaram a favor da introdução de procedimentos operacionais nas ciências sociais, como uma alternativa para se quantificar o que é qualitativo (GILLIES, 2000 $)$, o conceito de probabilidade de caso de Ludwig von Mises permanece radicalmente não numérico, orientado para as necessidades de compreensão histórica e empresarial.

\section{CONCLUSÃO}

Embora certas diferenças fundamentais entre as ciências naturais e as ciências sociais e a consequente necessidade de uma solução matizada para o problema de se encontrar uma definição adequada do conceito de probabilidade tenham sido reconhecidas por vários autores e escolas de pensamento, ambas as soluções para esse problema, conforme propostas por Ludwig von Mises e John Maynard Keynes, permanecem interessantes a partir de uma perspectiva teórica, assim como úteis de um ponto de vista prático.

Podemos concluir que os pontos de vista de Ludwig von Mises sobre a interpretação do conceito de probabilidade, determinados a partir de certas passagens de seus escritos, são em alguns aspectos mais parecidos com a interpretação lógica da probabilidade desenvolvida por John Maynard Keynes do que com a visão de frequência desenvolvida por seu irmão Richard von Mises. Em suma, pode-se aceitar essa conclusão apoiando-se no fato de que as visões de Ludwig von Mises e de John Maynard Keynes sobre a interpretação da probabilidade - isto é, sua filosofia de probabilidade - têm duas características importantes em comum que não são compartilhadas pela teoria da probabilidade de Richard von Mises.

Em primeiro lugar, Ludwig von Mises e John Maynard Keynes adotam uma interpretação epistemológica (ou epistêmica) da probabilidade, enquanto Richard von Mises adota claramente uma teoria objetiva da probabilidade. Os pontos de vista de Ludwig von Mises e John Maynard Keynes, na medida em que constituem um argumento para interpretar probabilidades na economia mais como epistemológicas que como objetivas, estão, portanto, de acordo com as conclusões de pesquisas recentes.

Em segundo lugar, Ludwig von Mises e John Maynard

cálculo matemático a diferentes conjuntos de fenômenos, conforme é o caso segundo outras visões dualistas da probabilidade. A distinção entre probabilidade de classe e de caso baseia-se, em última instância, no tipo diferente de acessibilidade cognitiva dos agentes humanos, em contraste com entidades não comunicativas. Veja Hoppe (2006 $)$.

36 A visão de Ludwig von Mises com respeito ao significado de probabilidade pode, assim, parecer ocupar um lugar verdadeiramente único na filosofia da probabilidade. John Hicks foi outro economista que adotou um ponto de vista cheio de nuances quanto a essa conexão. Ele escreveu: "Eu mesmo cheguei à visão de que a teoria da frequência, embora esteja presente em muitas das ciências naturais, não é suficientemente ampla para a economia." (HICKS, 1979, p. 105). Hicks está contrastando duas interpretações de probabilidade - a de frequência e a da lógica. A estrutura utilizada aqui é mais ampla desde que distingamos as teorias objetivas das teorias epistemológicas de probabilidade. 
Keynes, cada qual a seu modo, reconhecem a existência e a legitimidade epistemológica e científica das probabilidades não mensuráveis (ou não numéricas), bem como que as probabilidades mensuráveis usuais têm um valor numérico definido no intervalo [0, 1]. Embora Richard von Mises tenha reconhecido que havia uma linguagem comum ou um senso comum da noção de probabilidade que não era tratada por sua teoria de frequência, ele afirmou existir apenas um conceito de probabilidade que é de importância científica. Em outras palavras, de acordo com tal visão, inexiste, numa abordagem científica do assunto, qualquer espaço para uma noção puramente qualitativa da probabilidade.

Enquanto alguns autores chegaram a questionar a adequabilidade da teoria de frequência ortodoxa, mesmo para as ciências físicas, há um consenso significativamente maior a favor das conclusões (1) que, em qualquer caso, uma interpretação objetiva de probabilidade, como a teoria da frequência ortodoxa, não é suficientemente ampla para a Economia e (2) que, em Economia, um conceito qualitativo e não numérico da probabilidade é tão necessário quanto cientificamente legítimo. Ambas as características supramencionadas têm muita relevância para a condução das ciências sociais em geral e especialmente da economia.

Nesse ponto, uma diferença importante entre as opiniões de Ludwig Von Mises e as de John Maynard Keynes foi reconhecida. Enquanto Keynes defendia uma visão monista da probabilidade, alegando que sua interpretação de probabilidade aplica-se a todos os usos do conceito, Ludwig Von Mises, seguindo seu dualismo metodológico, adotou uma visão dualista, reconhecendo enfaticamente a existência de diferenças importantes entre as ciências naturais, por um lado, e as ciências sociais, incluindo a Economia, do outro. A solução particular oferecida por Ludwig von Mises permanece assim altamente distintiva e sofisticada, mesmo que comparada à abordagem keynesiana, tendo recebido até a presente época um pouco menos de atenção ${ }^{37}$.

\section{REFERÊNCIAS}

ADAMS, W. J. The Life and Times of the Central Limit Theorem. New York: Thaedmon Publishing, 1974.

ALBERT, David Z. Bohm's Alternative to Quantum Mechanics. Scientific American, 1994, p. 3239.

\footnotetext{
${ }^{37}$ Os economistas austríacos contemporâneos, que reconhecem a utilidade dos modernos métodos de análise de dados para a condução da pesquisa aplicada em economia, podem estar confiantes de que a prática cada vez mais ampla de interpretar probabilidades como meramente epistemológicas está de acordo com a abordagem de probabilidade feita por Ludwig von Mises. Além disso, não é claro e nem óbvio o porquê de o reconhecimento da utilidade dos métodos modernos de análise de dados ter que implicar em uma negação da importância essencial do método de compreensão ou Verstehen.
} 
BAGGOTT, J. Beyond Measure -Modern Physics, Philosophy and the Meaning of Quantum Theory. Oxford University Press, 2004.

$\mathrm{BOHR}, \mathrm{N}$. Discussion with Einstein on epistemological problems in atomic physics. In: SCHILPP, P. A. (Ed.). Albert Einstein: Philosopher- scientist, 1949, p.199-241.

CARNAP, R. The Two Concepts of Probability. Philosophy and Phenomenological Research, n. 5, 1945, p.513-532.

DE MUYNCK. W. M. Foundations of Quantum Mechanics an Empiricist Approach. London: Thluwer Academic Publishers, 2002.

$\underline{a} \underline{b} \underline{c}$ FINE, A. The Shaky Game-Einstein, Realism and the Quantum Theory. The University of Chicago Press, 1986.

FRAASSEN, Bas C. van. Quantum Mechanics: An Empiricist View. Oxford, 1991.

a $\underline{b}$ GALAVOTTI, M.C. Operationism, Probability and Quantum Mechanics. Foundations of Science, 1995, p. 99-118.

GILLIES, D. An Objective Theory of Probability. London: Methuen \& Co, 1973.

$\underline{a} \underline{b} \underline{c} \underline{d}$ GILLIES, D. Philosophical Theories of Probability. London: Routledge, 2000.

GNEDENKO, B.V. Theory of Probability. New York, 2005.

HEISENBERG W. Physics and Philosophy. London: Penguin Books, 1990.

HICKS, J. Causality in Economics. New York: Basic Books, 1979.

HOPPE, H.-H. Dissent on Keynes-A Critical Appraisal of Keynesian Economics. New York: Praeger, 1992, p. 199-223.

$\underline{a} \underline{b} \underline{c} \underline{d}$ HOPPE, H.-H. The Limits of Numerical Probability: Frank H. Thnight and Ludwig von Mises and the Frequency Interpretation. Procesos de Mercado-Revista Europea de Economía Política, v.3, n.2, p. 11-38, 2006. 
HOWSON, C. and P. Urbach. Scientific Reasoning-The Bayesian Approach. La Salle: Open Court Publishing, 2006.

HUGHES, R. I. G. The Structure and Interpretation of Quantum Mechanics. London: Harvard University Press, 1992.

$\underline{a} \underline{b} \underline{c}$ JAYNES, E. T. Probability Theory-The Logic of Science. Cambridge: Cambridge University Press, 2003.

$\underline{a} \underline{b} \underline{c} \underline{d}$ KEYNES, J. M. A Treatise on Probability. New York: Dover Publications, 2004.

KHRENNIKOV, A. Interpretations of Probability. Utrecht, 1999.

$\underline{a} \underline{b} \underline{c} \underline{d}$ LAD, F. The construction of probability theory. Science and Society, v. 47, p.285-99, 1983.

a $\underline{b}$ MISES, L. Von. The Ultimate Foundation of Economic Science. Thansas: Sheed Andrews and McMeel, 1978.

$\underline{a} \underline{b} \underline{c} \underline{d}$ MISES, Ludwig Von. Ação Humana. São Paulo: Instituto Ludwig von Mises Brasil, 2010.

$\underline{a} \underline{b} \underline{c} \underline{d}$ MISES, Ludwig Von. Teoria e História. São Paulo: Instituto Ludwig von Mises, 2014.

$\underline{a} \underline{b} \subseteq$ MISES, R. Von. Mathematical Theory of Probability and Statistics. New York: Academic Press, 1964.

MISES, R. Von. Positivism-A Study in Human Understanding. New York: Dover Publications, 1951.

$\underline{a} \underline{b} \underline{c} \underline{d}$ MISES, R. Von. Probability, Statistics and Truth. New York: Dover Publications, 1981.

POPPER, Th. R. Quantum Theory and the Schism in Physics. London: Hutchinson, 1982.

a $\underline{b}$ POPPER, Th. R. Realism and the Aim of Science, London: Hutchinson. Ramsey, F. P. (1988). In: GÄRDENFORS, P; SAHLIN, N. E. Truth and Probability (eds.). Decision, probability, and utility: Selected readings, Cambridge: Cambridge University Press, p. 19-47. 
Reimpresso de R. B. Braithwaite (ed.). The Foundations of Mathematics, London: Routledge and Thegan Paul, 1931, p. 156-198, 1983.

$\underline{a} \underline{b}$ ROTHBARD, M. N. Making Economic Sense. Auburn: Ludwig von Mises Institute, 1995.

ROTHBARD, M. N. Man, Economy, and State - The Scholar's Edition. Auburn: Ludwig von Mises Institute, 2004.

ROTHBARD, M. N. The Logic of Action I: Method, Money, and the Austrian School. Cheltenham: Edward Elgar, 1997.

RUNDE, J. Theynes After Ramsey-In Defence of A Treatise on Probability. Studies in History and Philosophy of Science, v.25, n.1, p. 97-121, 1994.

STEELE, D.R. Review of Justin Raimondo- An Enemy of the State: The Life of Murray N. Rothbard. Prometheus Books, local, 2000. 